\title{
Weighty matters: Body size, diet and specialization in aphidophagous ladybird beetles (Coleoptera: Coccinellidae)
}

\author{
JOHN J. SLOGGETT
}

Tussen Beide Markten 45, 9712 CC Groningen, The Netherlands; e-mail: johnsloggett@yahoo.co.uk

Key words. Body size, prey size, prey density, capture efficiency, dietary breadth, specialization, Coccinellidae, aphids

\begin{abstract}
Aphidophagous ladybirds exhibit a broad range of body sizes. Until now this has been thought to be a function of the different prey densities that they feed at, with smaller ladybirds feeding at lower prey densities. The size of the prey species they feed on has been considered to have no relationship with ladybird body size. However, these arguments possess a limited capacity to explain observed data from the field. I here demonstrate a more realistic, complex approach incorporating both prey density and the size of prey species. Small ladybirds can feed on small aphids at both low and high densities. However when the aphid species is large they cannot catch the older, bigger, more energy-rich aphid instars due to their small size. They are thus unable to feed on large aphid prey at low densities, although at higher densities numbers of the smaller instars may be sufficient to sustain them. By contrast large ladybirds can feed on large aphids at both low and high densities due to their superior ability to catch the bigger, more energyrich older aphids; however they cannot be sustained by low densities of small aphids due to food limitation consequent on their large size. This more complex association between ladybird size, prey size and prey density possesses a better explanatory power for earlier field data. Because of this relationship, ladybird body size also provides an important trade-off determining dietary breadth and specialization in the aphidophagous Coccinellidae. Dietary specialists more closely match the size of their limited prey species, have higher overall capture efficiencies and can thus continue to reproduce at lower aphid densities for longer. By contrast dietary generalists adopt a one-size-fits-all strategy, are medium-sized and have lower capture efficiencies of individual prey species, thus requiring higher aphid densities. The role of body-size in dietary specialization is supported by data from the British fauna. Rather than trade-offs related to prey chemistry, which have hitherto been the centre of attention, body size trade-offs are the likely most important universal factor underlying dietary specialization in aphidophagous coccinellids.
\end{abstract}

\section{INTRODUCTION}

Coccinellids display a wide diversity of size, even within groups. Amongst the North American aphidophagous Coccinellini, for example, the mass of the tiny Anisosticta bitriangularis is one-tenth of that of Anatis mali, a member of the genus containing the largest species. Since body size is an important determinant of a wide diversity of basic biological properties (e.g. Calder, 1984; Schmidt-Nielsen, 1984; Brown et al., 2004), it is unsurprising that this interspecific variation in body size in the Coccinellidae has attracted interest (Dixon, 2000). Across different coccinellid predatory groups, feeding on mites, coccids, aphids or non-homopteran prey, body size is related to prey size and mobility (Dixon \& Hemptinne, 2001). However, within these groupings, much work has only been carried out on the aphidophages. Here, it has been claimed that there is no relationship between body size and prey size (Dixon \& Stewart, 1991; Stewart et al., 1991) but that variation in body size is related to prey density (Dixon, 2007). However the validity of this analysis is open to question, as a considerable body of evidence exists that is not consistent with these hypotheses (e.g. Banks, 1955; Elliott \& Kieckhefer, 1990; Liu et al., 2004).

Dietary specialization within the aphidophagous Coccinellidae may also be considered a contentious area. Here a view that dietary breadth arises as a consequence of trade-offs related to prey chemistry has tended to pre- dominate (Rana et al., 2002), although alternative perspectives exist (Sloggett \& Majerus, 2000a). Again, in this area there is evidence that does not support the predominant view (Ueno, 2003; Fukunaga \& Akimoto, 2007).

In this paper I will reconsider both these areas and show that one overlooked fact - that body size and prey size are related to each other after all - can not only explain the anomalous evidence about body size, but can provide a universal solution to questions about the nature of trade-offs in determining dietary breadth and specialization in aphidophagous coccinellids.

\section{INTERSPECIFIC VARIATION IN BODY SIZE AND ITS CAUSES}

\section{The established view}

Aphid density has been considered the major determinant of body size in aphidophagous coccinellids (Dixon, 2007). The relationship between coccinellid body size and prey density is a function of two factors. The amount of food a coccinellid needs to maintain itself or for reproduction scales with body weight or mass $\left(W t^{1}\right)$ (Dixon, 2007). However additionally larger coccinellids move faster and have a wider area of perception, thus the area searched per unit time is greater for larger coccinellids, scaling as $W t^{0.66}$ (Dixon \& Stewart, 1991; Dixon, 2007). Taking these two factors together indicates that aphid density scales as $W t^{1} / W t^{0.66}$ or $W t^{0.33}$ : thus, Coccinella sep- 
tempunctata, a large ladybird of about $35 \mathrm{mg}$ needs approximately 1.5 the density of aphids to sustain reproduction as that needed by Adalia bipunctata, a small ladybird of approximately $10 \mathrm{mg}$ (Dixon, 2007). This idea suggests that as aphid colonies develop they should be used for oviposition by small ladybirds first, when aphid densities are lower and large ladybirds later as aphid densities increase (Dixon, 2007; Fig. 1A).

In spite of the evidence from different coccinellid predatory groups (Dixon \& Hemptinne, 2001), it has been argued that there is no relationship between the body size of different aphidophagous ladybirds and the prey that they consume i.e. that larger ladybirds do not consume larger prey (Dixon \& Stewart, 1991; Stewart et al., 1991; Dixon, 2007). This is based on a comparison of prey sizes of seven aphidophagous ladybirds of different sizes (Stewart et al., 1991). The authors obtained lists of prey (Scheurer, 1971; Mills, 1981) and their sizes from the literature to do this. No correlation between prey weight and adult or egg weight was found, nor did comparisons between the largest and smallest species give any indication of a difference (Stewart et al., 1991).

\section{Problems and criticisms}

Undoubtedly examples may be found that do show smaller ladybirds exploiting colonies earlier: for example, soybean aphids, Aphis glycines, tend to be attacked by smaller ladybirds earlier in the season than larger ladybirds (Mignault et al., 2006) and the smaller ladybird Menochilus sexmaculatus oviposits earlier than the larger Coccinella transversalis on the aphid Aphis craccivora (Agarwala \& Bardhanroy, 1999). However, many contrary examples also exist. For example, data from a thirteen year survey of alfalfa indicate that as the season progresses the ladybird species reproducing there get smaller (Elliott \& Kieckhefer, 1990). Similarly studies of one of the largest aphidophagous ladybirds in North America, Anatis mali, indicate that this species utilizes low aphid densities (Gagné \& Martin, 1968). It is therefore clear that a simple body size-density relationship can only explain some observations from the field.

There are considerable problems with the apparent absence of a relationship between ladybird body size and aphid size, as the approach used thus far fails to take into account the complexity of the predator-prey relationship. As noted already, Stewart et al. used species-specific prey lists from the literature to examine the relationship between predator and prey size. However, lists do not distinguish between infrequently- and frequently-utilized prey. For example, Anatis ocellata, a specialist on pine aphids (e.g. Scheurer, 1971; Majerus, 1994), will on odd occasions reproduce on aphids on deciduous trees (J.J. Sloggett, pers. obs.). Thus, while some aphids of deciduous trees warrant inclusion on a list of essential prey consumed in the field (cf. Mills, 1981), these aphids are not the characteristic prey of $A$. ocellata. Because of differences in the frequency of occurrence of coccinellids with different aphid prey, the use of prey lists without some form of weighting of prey species according to the extent to which they are used is unlikely to detect an asso-
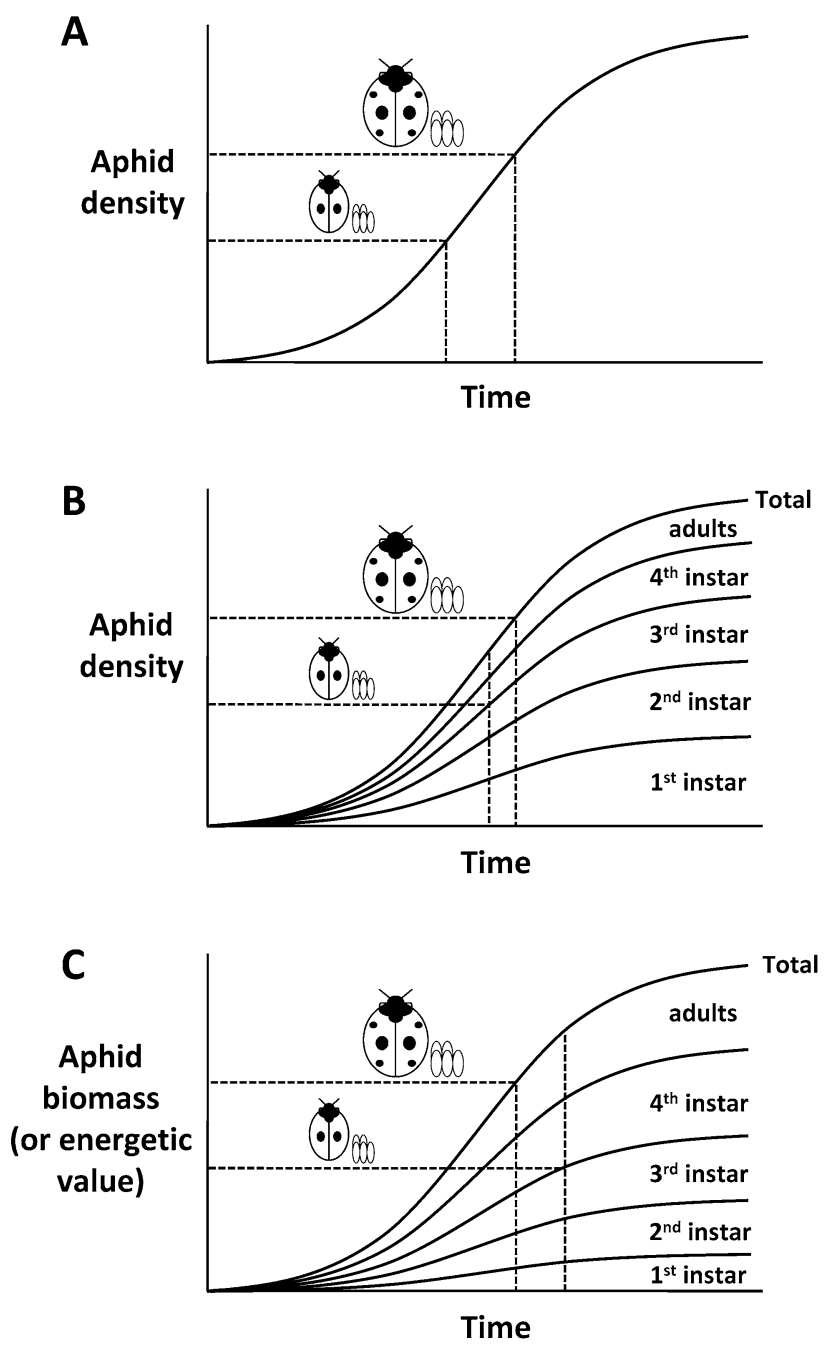

Fig. 1. Diagrammatic view of the relationship between prey abundance and ladybird body size. In each case the horizontal dashed lines represent the prey threshold necessary for reproduction by the large (upper line) and small (lower line) ladybirds. The vertical dashed lines show the total aphid abundance and time at which reproduction is possible for each of the species. (A) The established view of Dixon (2007). Here there is no relationship between ladybird body size and capture efficiency as might occur with small aphid species. Small ladybirds require a lower density of aphids for reproduction on account of their lower energetic requirements (see text for details) and can thus reproduce earlier in the development of an aphid population. (B) Total aphid density required by the small ladybird is increased if the small ladybird, on account of its size, is unable to catch larger aphid instars (in this case fourth instars and adults): this might occur with large aphid species. Aphid density is broken down into the proportions of the different instars occurring. This graph does not take into account the differences in size and energetic content of the different aphid instars but only numerical abundance. (C) A similar, but more realistic graph than B taking into account the different energetic values of different instars. Because the small aphid instars which can be caught by the small ladybird are more energy poor than the average aphid, this acts to make the total abundance of aphids necessary for reproduction higher still, leading to a situation where the small ladybird reproduces later than the large one. 
ciation even if it exists, as rare, potentially atypicallysized prey are considered equal to common prey. Lists are likely to be adequate when looking for size associations of different predator groupings (i.e. aphidophagous, coccidophagous, etc.) with their prey (cf. Dixon \& Hemptinne, 2001) as membership of such groupings is near-discrete and easy to classify; however, the use of prey species within the predator groups does not present such a simple pattern and consequently conclusions based upon uninterpreted lists may be misleading.

More importantly still, the aphids of one species are not all the same size: aphid nymphs are far smaller than adults and this must be considered when thinking about the relationship between ladybird and aphid body sizes. For a single aphid species, big and small ladybirds are likely to be exploiting big and small aphid instars differently. This is particularly true in the case of large aphid species where the relative size of predator and prey are likely to affect capture efficiency. This is known to be the case in larval ladybirds (e.g. Dixon, 1959; Klingauf, 1967) and there is no reason to assume that it is otherwise in adults. Small ladybirds would be able to catch small aphid species and the smaller instars of larger aphids, but are unlikely to be as effective as large ladybirds at overwhelming the older, bigger instars, especially in large aphid species. Observations in the field support this view: adults of the large Cinara aphid species of conifers are easily caught by big adult ladybirds such as Myzia oblongoguttata and Anatis ocellata but are rarely captured by adults of the small Myrrha octodecimguttata which they can easily kick away (J.J. Sloggett, pers. obs.). Similarly in the laboratory both Hippodamia convergens, which is larger and Hippodamia parenthesis, which is smaller, can catch pea aphids, Acyrthosiphon pisum, equally well up to the aphid third instar. However, in the cases of fourth instar and adult aphids the larger $H$. convergens is the more effective predator (J.J. Sloggett, unpub. data).

\section{Integrating prey size and density}

There are thus a number of objections to the earlier view of aphidophagous ladybird body size that suggest that the relationship between body size and aphid density currently argued for (Dixon, 2007) is too simple. In fact, body size in aphidophagous ladybirds has a more complex basis, related to both prey size and density.

A diagrammatic version of Dixon's model is shown in Fig. 1A. Smaller ladybirds reproduce at lower total aphid densities and thus reproduce earlier in the development of aphid populations when densities are lower. This model will hold true when both big and small ladybirds have equal probabilities of catching the aphid prey and is likely to be the case when the prey is a small aphid species. Individuals of small species of aphid are easily overwhelmed and captured by both big and small ladybirds, even the bigger, older aphid instars, which are still in absolute terms small. In this case it is the searching and food requirement of ladybirds which will determine when they can reproduce, rather than capture efficiency which is likely to be universally high. Both of these factors are incorporated into Dixon's $W t^{0.33}$, as shown above.
But in the case of large aphid species, big and small ladybirds do not have an equal probability of catching the aphid prey. Big ladybirds, by virtue of their size, are more efficient at overwhelming the larger, older instars of these species, although small ladybirds can still catch the smaller instars. This alters the relationship between body size and aphid abundance or density as shown in Fig. 1B and $1 \mathrm{C}$. In these figures, the larger ladybird species is able to catch all the instars of the prey aphid, but the smaller ladybird can only catch the small first three instars.

Two additional factors now come into play. First, while the larger ladybird is able to exploit all the aphids in the population, the small ladybird is only able to exploit a proportion of them (third instars and smaller): it therefore needs an increased total aphid density to catch the same number of aphids because the aphid density necessary for this species to reproduce only includes aphids up to the third instar (Fig. 1B).

Second, the biggest aphids, which the smaller ladybird cannot catch, are the most energy rich. For example, if adult aphids have a mass ten times that of first instars, a ladybird must eat ten first instar aphids to obtain the same energy as it would from eating one adult aphid. The consequences for ladybird predators of different sizes are shown in Fig. 1C. While the bulk of the aphid numbers in a population are smaller instars (Fig. 1B) much or even most of the biomass is concentrated in the bigger older instars even though they occur less frequently (Fig. 1C). This means that in addition to only being able to catch a fraction of the aphids that can be caught by the large ladybird, the small ladybird gets a lower average energetic return from each individual prey it does catch and will need yet higher aphid abundances before it can reproduce. Overall this means that when exploiting large aphid species, small ladybirds are many times less efficient than large ladybirds and are likely to need a higher total prey density than large species for reproduction (Fig 1C): they will therefore reproduce later or even not at all. A mathematical formulation of this model, combined with supportive data for Hippodamia convergens and Hippodamia parenthesis feeding on the aphid Acyrthosiphon pisum will be published shortly.

Put more simply, small ladybirds can exploit lower densities of small aphid species than large ladybirds by virtue of their lower food requirement. By contrast, large ladybirds can exploit lower densities of large aphid species than small ladybirds by virtue of their higher feeding efficiency. In consequence there is a relationship between predator size and prey size, but it is not the rigid relationship looked for by Stewart et al. (1991). Large ladybirds can feed on high densities of small aphids and small ladybirds on high densities of large aphids, but both will generally be better at exploiting aphids more closely matching them in relative size than aphids of other sizes.

\section{Does the evidence support the prey size-density hypothesis?}

The prey size-density hypothesis outlined here can explain much of the contradictory data in the literature. 
With small aphids, such as $A$. craccivora and $A$. glycines, small ladybirds do appear to arrive and breed earlier and at lower aphid densities than larger ladybird species (Agarwala \& Bardhanroy, 1999; Mignault et al., 2006). However with larger aphids the opposite does indeed appear to be the case. In particular data from alfalfa, where the predominant aphid is often the relatively large A. pisum support the argument. The large Coccinella septempunctata can exploit pea aphids in alfalfa at lower aphid densities than American native species (Evans, 2004), which are generally smaller. Furthermore, as noted already, as the season progresses the ladybird species reproducing there get smaller (Elliott \& Kieckhefer, 1990). The prey size-density hypothesis can also explain why large ladybirds such as Anatis species perform well at low aphid densities on pine trees (Gagné \& Martin, 1968): although both large and small aphids occur together on pine trees simultaneously (e.g. Sloggett \& Majerus, 2000b), the large Cinara species are much more easily captured by the large conifer specialists making a greater total aphid biomass available to them.

There are few cases where ladybird occurrence with a large and a small aphid species have been included in a single study, although such studies arguably provide the best test of all for the prey size-density hypothesis. However, Banks' (1955) British study of aphids and ladybirds on broad bean and nettle provides an example of a wellknown, frequently-cited study which did attempt this. His results provide good support for the prey size-density argument. On broad bean (Vicia faba) infested with the small Aphis fabae, in a plot with the lowest aphid densities, the relatively small ladybird Adalia bipunctata as well as the similarly-sized Propylea quatuordecimpunctata were observed earlier, apparently breeding, when aphid densities were reduced; the larger Coccinella septempunctata only appeared later. By contrast in plots with a higher density of $A$. fabae this difference is less pronounced, presumably because during the study period the density of the small aphid was sufficiently high to sustain the bigger ladybird. On nettles (Urtica dioica) infested by the larger aphid, Macrosiphon evansi (= Microlophium carnosum), C. septempunctata clearly appears in extremely large numbers earlier than the smaller species. Bank's results are noteworthy not only for the very full picture that they provide but because $A$. fabae is generally considered rather unsuitable for $A$. bipunctata compared with many other aphids (Blackman, 1965, 1967a; ElHariri, 1966). In this case it appears that prey size and density were the major determinants of ladybird occurrence rather than prey chemistry and consequent dietary suitability.

The discussion thus far has been formulated primarily with the aphidophagous Coccinellini in mind. Aphidophagous ladybirds of other groups such as the Scymnini are much smaller than even the smallest Coccinellini and in the case of these very small ladybirds, it seems probable that lower capture efficiencies of the larger stages of even small aphid species may invariably necessitate the exploitation of high aphid densities. Populations of
Scymnus babai (Scymnini) peak after those of the larger Propylea japonica (Coccinellini), at higher aphid densities, in Aphis glycines-infested soybean in China (Liu et al., 2004): although $A$. glycines is a small aphid in absolute terms, an adult is large for a Scymnus ladybird to catch. Ladybirds of very small size may, on account of this, be limited to exploiting high densities of any aphid whatever its size.

\section{BODY SIZE, DIETARY BREADTH AND SPECIALIZATION}

\section{Specialization, trade-offs and body size}

Aphidophagous ladybirds are very variable in their dietary breadth. Some species are near-monophagous, such as Anisosticta novemdecimpunctata which feeds predominantly on Hyalopterus pruni in its specialist reed-bed habitat, while others such as Adalia bipunctata and Coccinella septempunctata feed and breed on tens or even hundreds of different aphid species (Majerus, 1994; Hodek, 1996; Klausnitzer \& Klausnitzer, 1997). The evolutionary causes of dietary specialization have been extensively studied for a long time in phytophagous insects, but only relatively recently have we begun to study and understand the factors responsible for dietary specialization in predators including ladybirds (Bristow, 1988; Tauber et al., 1993; Sloggett, 2008).

The intrinsic underlying framework for the evolution of specialization is provided by fitness trade-offs for the predator operating between different types of prey. That is, evolved adaptations to facilitate high fitness on one type of prey necessarily entail a decline in fitness with other prey types. Specialists perform very well on a few prey types, but badly on other potential prey, whereas generalists perform moderately well on the differing components of a wider prey spectrum. Such trade-offs are expected to be operating: if there is no such correlated cost to strong adaptation to a particular prey, there is no underlying rationale to specialization. While a number of different potential trade-offs have been suggested to underlie ladybird dietary breadth (Sloggett \& Majerus, 2000a; Rana et al., 2002; Sloggett, 2008), there has been rather less in the form of sound experimental evidence: their exact nature has remained a matter for debate and discussion.

Most interest thus far has been concentrated on tradeoffs related to prey chemistry, a consequence of aphids feeding on their host plants. Under this hypothesis the suitability of an aphid to sustain growth and reproduction without toxic effects will be traded-off against the suitability of other prey species. This approach is rooted in studies of the dietary specialization in phytophagous insects, where trade-offs involving the ability to tolerate plant defensive compounds are considered to be important factors in dietary specialization (e.g. Jaenike, 1990; Schoonhoven et al., 1998); it also continues a long tradition of work on prey suitability in ladybirds, which is often still viewed predominantly in terms of prey content, particularly defensive chemicals (Hodek, 1973, 1996; Michaud, 2005). There have been three tests of chemistry 
related trade-offs on different prey (Rana et al., 2002; Ueno, 2003; Fukunaga \& Akimoto, 2007), but only one of these has claimed to find any evidence for a chemical trade-off (Rana et al., 2002), and even in this case, the results are open to question (Sloggett, 2008). Prey chemistry therefore does not appear to be a universal or even a primary trade-off underlying the evolution of dietary specialization in aphidophagous ladybirds.

However body size could play such a role. A specialist that feeds on a single species of aphid is likely to be of optimum size to catch and utilize this aphid for breeding: that is big enough to catch all aphid instars, but not bigger so that it needs unnecessarily high aphid densities to reproduce. In other words, its relative size will very closely match that of its prey. In the case of small prey, a specialist is also small: it is unnecessary to be larger to catch their aphid and small size facilitates the exploitation of low aphid densities. Specialists on large aphid species are large: in that way it is possible for them to exploit the full size spectrum of their aphid prey rather than merely the smallest, and again to exploit lower prey densities. Because specialists exhibit a greater overall capture efficiency and can exploit lower densities of aphids they can remain associated with one type of aphid prey for longer: itself a necessary phenological prerequisite for specialization.

By contrast, generalist predators are likely to adopt a one-size-fits-all strategy: they will tend to be of a medium size to exploit a wide prey spectrum comprising aphids of different sizes. However, in doing this they will be less efficient in exploiting most types of prey, because they need more of smaller aphid species to reproduce and cannot catch the largest individuals of big aphid species: they therefore require higher densities of most aphid species for effective reproduction.

This (summarized in Fig. 2) is a classical trade-off in which strong body-size adaptation to any one aphid species necessarily entails a lowered efficiency (i.e. fitness) on other aphids. Overall this suggests that dietary specialist ladybirds should exhibit a greater range of sizes, because each specialist is adapted to differently-sized aphid species, and that generalists, by virtue of feeding on a spectrum of aphids that vary in size will exhibit a narrower range of body sizes in the middle of the ladybird size spectrum.

More specialized species appear to be able to exploit lower densities of aphids than generalists in comparable habitats: for example the pine specialists Anatis mali and Mulsantina picta are able to exploit older pine trees with lower prey densities than more generalist Coccinella species (Gagné \& Martin, 1968). Similarly the more specialized Adalia decempunctata is found at lower aphid densities than its generalist sibling species Adalia bipunctata (Honěk, 1985). This provides some support for the specialist-generalist body size argument, although other forms of adaptation to particular prey (e.g. specialized foraging behaviour) could also explain this pattern. A good test of whether body size is a factor explaining dietary specialization is to compare the sizes of specialist

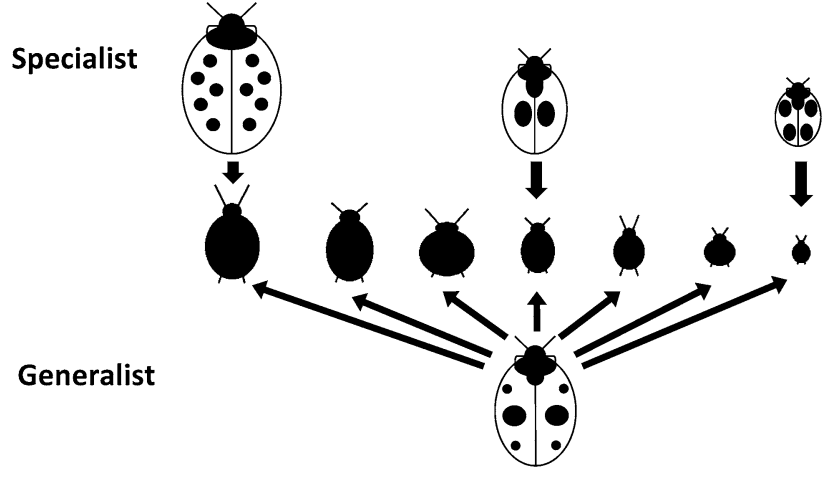

Fig 2. Diagrammatic summary of the body sizes of dietary specialists and generalists in relation to aphid size. Specialists that feed on a few types of aphid will closely match their prey in size whereas generalists, which feed on prey of a diversity of sizes, will be medium sized. In consequence specialists are expected to display a wider diversity of sizes than generalists.

and generalist ladybirds: if body size is important specialists should display a greater diversity of size (Fig. 2).

\section{A test of the body size-dietary breadth hypothesis}

I have tested this specialization-size diversity hypothesis here for native British aphidophagous Coccinellini. This group was chosen for a number of reasons. The use of large faunal groups (e.g. all Palaearctic or Nearctic species) is undesirable because there are still so many gaps in our knowledge of the dietary preferences of many coccinellid species: this is even true for more species-rich countries than Britain, for example Germany (Klausnitzer \& Klausnitzer, 1997). By contrast the entire British fauna is well known both through published work (e.g. Majerus, 1994) and to the author personally. Large geographic regions are also likely to contain closely related allopatric species of similar size and diet, such as occurs with pine specialists of the genera Anatis and Myzia in North America (Gordon, 1985). There is a consequent danger of phylogenetic pseudoreplication (multiple data points representing a single evolutionary event) which is avoided in the British data as although there are some close relatives among British species (e.g. Coccinella spp.) they differ in either size and/or ecology. The Coccinellini were chosen as they form a monophyletic group with broadly similar biological characteristics that is the best known of the coccinellids: even within the British fauna the diet within other groups such as the Scymnini is more poorly known.

The native British Coccinellini that are generally considered aphidophagous comprise a total of seventeen species (Majerus, 1994). One of these species, Coccinella hieroglyphica, was excluded from my analysis as there is some evidence that this beetle is a frequent consumer of the immature stages of chrysomelid beetles (e.g. Hippa et al., 1978, 1984; Sloggett \& Majerus, 1994). On the basis of my own observations and those of Majerus (1994) I subdivided the remaining sixteen species into dietary specialists and generalists (Table 1). This is to some extent an artificial division as dietary breadth is a continuum rather than a dichotomy. My sole criterion for the division was diet. Some habitat-specific coccinellids still consume 
TABLE 1. Dichotomization of the British aphidophagous Coccinellini into dietary generalists and specialists. A brief description of the habitat of dietary specialists is shown, as a simple (though imperfect) indicator of their dietary breadth. For more detail see text and Majerus (1994); further discussion of the differences between conifer specialists may be found in Sloggett \& Majerus (2000b) and incl. refs.

\begin{tabular}{ll}
\hline Generalists & Specialists \\
\hline Adalia bipunctata & Adalia decempunctata (trees and shrubs) \\
Calvia quatuordecimguttata & Anatis ocellata (conifers) \\
Coccinella magnifica & Anisosticta novemdecimpunctata (reed beds) \\
Coccinella quinquepunctata & Aphidecta obliterata (conifers) \\
Coccinella septempunctata & Harmonia quadripunctata (conifers) \\
Coccinella undecimpunctata & Hippodamia tredecimpunctata (reed beds, marsh) \\
Hippodamia variegata & Myrrha octodecimguttata (conifers) \\
Propylea quatuordecimpunctata & Myzia oblongoguttata (conifers) \\
\hline
\end{tabular}

a relatively high diversity of prey. For example, Coccinella magnifica, which is restricted to the vicinity of Formica rufa ant colonies in Britain, consumes a wide diversity of aphid prey in its specialized habitat (Sloggett et al., 2002): thus in my dichotomy C. magnifica is considered a generalist. Species sizes were obtained as body lengths from Iablokoff-Khnzorian (1982): as a range of sizes are given for each species I used the median value for each size range. I used the Moses rank-like test for scale differences to compare the distributions of the sizes of specialists and generalists: this is a test for overall dispersion of the data (Siegel \& Castellan, 1988). As there were eight species in both groups (generalist and specialist), I used four subsets of two data points for each group in the analysis. Because there was a clear hypothesis to be tested (dispersion of the sizes of specialists $>$ dispersion of the sizes of generalists), a one-tailed test was used.

Results are shown in Fig. 3: it is clear from this that the size distribution of specialists is broader than that of generalists. This was supported by the Moses test $(W=10, m$ $=n=4, P=0.014)$. Generalists do appear to be all medium sized: at the extremes, both the largest two ladybirds (Anatis ocellata and Myzia oblongoguttata) and the smallest two (Anisosticta novemdecimpunctata and Aphidecta obliterata) are all specialists.

There are also four specialists within the size range exhibited by generalists. The body size-dietary breadth

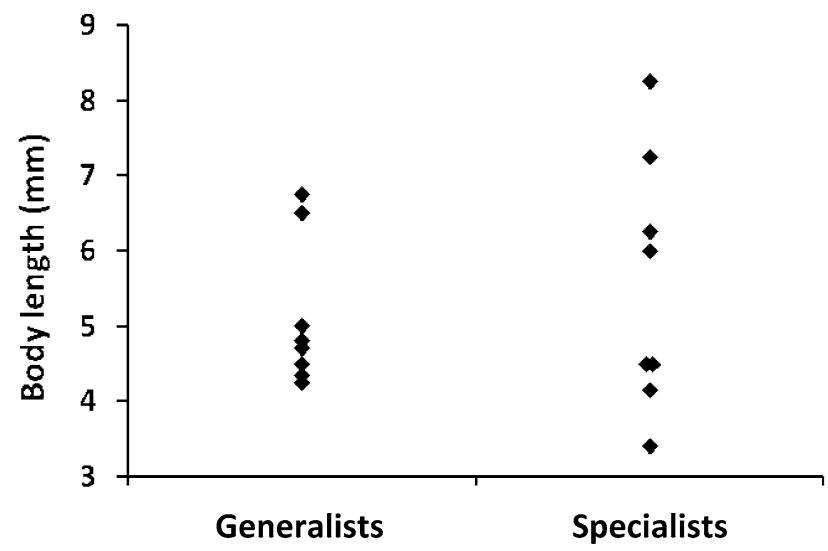

Fig. 3. The distribution of body sizes in dietary generalists and specialists belonging to the native British aphidophagous Coccinellini. hypothesis does not exclude this occurrence, but merely states that specialists should more closely match their prey in size, leading to higher overall range of specialist body sizes. However this is important when considering whether body size constitutes a viable trade-off. Phylogeny probably exerts a limiting influence on dietary breadth: a medium-sized dietary specialist is unlikely to spontaneously broaden its dietary breadth, even if it may prosper elsewhere because of its size (see Sloggett \& Majerus, 2000a on possible factors responsible for dietary shifts). Additionally, of the four medium-sized specialists, three (Adalia decempunctata, Harmonia quadripunctata and Hippodamia tredecimpunctata) are arguably dietarily less specialized than the four specialists of extreme sizes (see Majerus, 1994; Sloggett \& Majerus, 2000a, b for prey or habitat details). The fourth, Myrrha octodecimguttata is a highly specialized conifer aphid specialist (Klausnitzer, 1968; Majerus, 1988), but like all the conifer specialists it feeds on trees colonized by aphids of a variety of sizes (Blackman \& Eastop, 1994): arguably the different conifer specialists have reached different prey size/density optima when exploiting the same aphid prey spectrum. It is perhaps worth noting that conifer specialists are particularly numerous within the aphidophagous coccinellids (Iablokoff-Khnzorian, 1982; Chapin, 1985; Gordon, 1985), thus any apparent bias in my sample of specialists reflects a genuine bias in the coccinellid fauna.

Interestingly, as noted previously by Dixon \& Stewart (1991), the size distribution is overall bimodal: this appears to be true for both groups. Since Dixon \& Stewart did not consider coccinellid body size to be related to prey size they assumed that this bimodal distribution had some other cause: however its relationship to prey size is worthy of reinvestigation in the future. Irrespective of the bimodal distribution, the data set clearly supports the view that specialists more closely match the size of their prey whereas generalists adopt a one-sizefits-all strategy. Body size therefore is a trade-off of likely considerable importance in determining prey specialization due to its relationship with both prey size and density. 


\section{CONCLUSIONS}

In this paper I have shown that the body size of ladybirds is not just a function of aphid density, but of a more complex interaction between both density and prey size. It would be interesting to know whether such arguments also hold true for other predator groupings within the Coccinellidae, such as those preying on mites and coccids, as well as beyond the Coccinellidae. It is also necessary to look again at the immature stages of coccinellids. Stewart et al. (1991) also failed to find any relationship between aphid size and the egg size of aphidophagous coccinellids. This is perhaps surprising in view of their contention that prey size places a minimum constraint on the size of eggs that ladybirds can lay; it is noteworthy that they also demonstrated a positive correlation between egg and adult mass. In considering egg size and the size of the consequent neonate larvae, the situation is complicated because egg size and number can be optimized to maximize parental fitness: that is parents can produce smaller less efficient larvae if they also produce more of them. Further complexity is provided by hypothesized developmental constraints (Stewart et al., 1991), neonate larval foraging adaptations (Hemptinne et al., 2000) and interspecific differences in egg composition (Sloggett \& Lorenz, 2008). Considered overall the factors governing egg size arguably require a thorough reevaluation.

Although many factors influence whether a prey type is suitable and included in the diet of a predator, the key factor to understanding the evolution of dietary specialization in any organism is the operation of trade-offs: that is if an organism evolves an adaptation to one particular food type, this must necessarily entail some sort of correlated decline in fitness when feeding on other types of food. Body size trade-offs are of likely great significance as factors determining dietary breadth and specialization in aphidophagous ladybirds: the evolution of an optimal body size to exploit one aphid type will entail a decline in capture efficiency on prey of other sizes. Placed in its correct context, body size is probably of much greater importance as a trade-off underlying dietary specialization than adaptation to prey chemistry: in the case of the latter, the studies thus far have failed to find evidence for any sort of universal trade-off.

There are perhaps good reasons for this. Capture efficiency, which is consequent on body size, is arguably the most fundamental property necessary to exploit prey. No matter how suitable or unsuitable the prey chemistry, if it is not possible to catch sufficient prey, then the prey cannot be utilized for reproduction. This is particularly important in ladybirds where the adult insect feeds on aphids and the amount of aphids consumed directly affects the number of eggs produced (e.g. Dixon \& Guo, 1993). It is particularly well demonstrated by Banks' (1955) paper, discussed above, in which $A$. bipunctata reproduce early on the chemically less suitable $A$. fabae but not on the more suitable $M$. evansi; this, as discussed, is a consequence of $A$. bipunctata's body size.
Body size and capture efficiency also provide a direct link between preference (i.e. where a ladybird lives) and performance (i.e. its fitness on a given resource). Ladybirds which encounter aphid prey of the "wrong" size or density are unlikely to remain in these colonies for long due to a lack of food and likely to lay few or no eggs there: thus "preference" could be a passive process mediated by satiation. Over evolutionary time, particularly in specialists, a response to cues which indicate the best type of habitat in which to find the "right" aphid colonies may evolve (e.g. response to pine volatiles in Anatis ocellata: Kesten, 1969); however, strict discrimination of different aphid species is not really necessary. It is noteworthy that studies centred on prey chemical dietary suitability have provided ambiguous and contradictory evidence for any preference-performance link (Blackman, 1967b; Omkar \& Mishra, 2005; Fréchette et al., 2006).

Clearly body size is important and its implications go well beyond simply prey density. The idea that body size and prey size are unrelated has become sufficiently embedded in the literature as to influence other areas of the study of coccinellid biology where it may also have a bearing. Such areas are potentially diverse, not only encompassing prey specialization and reproductive strategy but more topical areas such as invasive species and their interaction with native ladybirds, as well as intraguild predation (e.g. Evans, 2004; Omkar et al., 2006; Ware \& Majerus, 2008). As with prey specialization, workers in some of these areas may need to re-evaluate hypotheses concerning body size or reconsider whether body size may play a hitherto unforeseen role in their studies.

ACKNOWLEDGEMENTS. I wish to thank I. Hodek, J.P. Michaud, I. Zeilstra and an anonymous referee for their valuable comments on an earlier draft of this manuscript.

\section{REFERENCES}

Agarwala B.K. \& Bardhanroy P. 1999: Numerical response of ladybird beetles (Col., Coccinellidae) to aphid prey (Hom., Aphididae) in a field bean in north-east India. J. Appl. Entomol. 123: 401-405.

BANKs C.J. 1955: An ecological study of Coccinellidae (Col.) associated with Aphis fabae Scop. on Vicia faba. Bull. Entomol. Res. 46: 561-587.

Blackman R.L. 1965: Studies on specificity in Coccinellidae. Ann. Appl. Biol. 56: 336-338.

Blackman R.L. 1967a: The effects of different aphid foods on Adalia bipunctata L. and Coccinella 7-punctata L. Ann. Appl. Biol. 59: 207-219.

BLACKMAN R.L. 1967b: Selection of aphid prey by Adalia bipunctata L. and Coccinella 7-punctata L. Ann. Appl. Biol. 59: $331-338$.

Blackman R.L. \& Eastop V.F. 1994: Aphids on the World's Trees. An Identification and Information Guide. CAB International, Wallingford, $987 \mathrm{pp}$.

BRISTOw C.M. 1988: What makes a predator specialize? Trends Ecol. Evol. 3: 1-2.

Brown J.H., Gillooly J.F., Allen A.P., Savage V.M. \& West G.B. 2004: Towards a metabolic theory of ecology. Ecology 85: 1771-1789. 
Calder W.A., III 1984: Size, Function and Life-History. Harvard University Press, Cambridge, MA, $431 \mathrm{pp}$.

Chapin J.B. 1985: Revision of the genus Mulsantina Weise (Coleoptera: Coccinellidae). Ann. Entomol. Soc. Am. 78: 348-368.

Dixon A.F.G. 1959: An experimental study of the searching behaviour of the predatory coccinellid beetle Adalia decempunctata (L.). J. Anim. Ecol. 28: 259-281.

Dixon A.F.G. 2000: Insect Predator-Prey Dynamics: Ladybird Beetles and Biological Control. Cambridge University Press, Cambridge, 268 pp.

Dixon A.F.G. 2007: Body size and resource partitioning in ladybirds. Popul. Ecol. 49: 45-50.

Dixon A.F.G. \& Guo Y.Q. 1993: Egg and cluster size in ladybird beetles (Coleoptera: Coccinellidae): The direct and indirect effects of aphid abundance. Eur. J. Entomol. 90: 457-463.

Dixon A.F.G. \& HemptinNe J.-L. 2001: Body size distribution in predatory ladybird beetles reflects that of their prey. Ecology 82: $1847-1856$.

Dixon A.F.G. \& Stewart L.A. 1991: Size and foraging in ladybird beetles. In Polgár L., Chambers R.J., Dixon A.F.G. \& Hodek I. (eds): Behaviour and Impact of Aphidophaga. SPB Academic Publishing, The Hague, pp. 123-132.

EL-HaRiRI G. 1966: Laboratory studies on the reproduction of Adalia bipunctata (L.) (Col., Coccinellidae). Entomol. Exp. Appl. 9: 200-204.

ELLIOTT N.C. \& KiECKHEFER R.W. 1990: A thirteen year survey of the aphidophagous insects of alfalfa. Prairie Nat. 22: $87-96$.

Evans E.W. 2004: Habitat displacement of North American ladybirds by an introduced species. Ecology 85: 637-647.

Fréchette B., Dixon A.F.G., Alauzet C., Boughenou N. \& Hemptinne J.-L. 2006: Should aphidophagous ladybirds be reluctant to lay eggs in the presence of unsuitable prey? Entomol. Exp. Appl. 118: 121-127.

Fununaga Y. \& Акімото S. 2007: Toxicity of the aphid Aulacorthum magnoliae to the predator Harmonia axyridis (Coleoptera: Coccinellidae) and genetic variance in the assimilation of the toxic aphids in H. axyridis larvae. Entomol. Sci. 10: $45-53$.

Gagné W.C. \& Martin J.L. 1968: The insect ecology of red pine plantations in central Ontario. V. The Coccinellidae (Coleoptera). Can. Entomol. 100: 835-846.

Gordon R.D. 1985: The Coccinellidae (Coleoptera) of America north of Mexico. J. N. Y. Entomol. Soc. 93: 1-912.

Hemptinne J.-L., Gaudin M., Dixon A.F.G. \& Lognay G. 2000: Social feeding in ladybird beetles: adaptive significance and mechanism. Chemoecology 10: 149-152.

Hippa H., Koponen S. \& Laine T. 1978: On the feeding biology of Coccinella hieroglyphica L. (Col., Coccinellidae). Rep. Kevo Subarctic Res. Stat. 14: 18-20.

Hippa H., Koponen S. \& RoIne R. 1984: Larval growth of Coccinella hieroglyphica L. (Col., Coccinellidae) fed on aphids and preimarginal stages of Galerucella sagittariae (Col., Chrysomelidae). Rep. Kevo Subarctic Res. Stat. 19: 67-70.

Hodek I. 1973: Biology of Coccinellidae. Academia, Prague, $260 \mathrm{pp}$.

Hodek I. 1996: Food relationships. In Hodek I. \& Honěk A (eds): Ecology of Coccinellidae. Kluwer Academic Publ., Dordrecht, pp. 143-238.

HoNĚK A. 1985: Habitat preferences of aphidophagous coccinellids (Coleoptera). Entomophaga 30: 253-264.

IABlokoff-Khnzorian S.M. 1982: Les Coccinelles. Coléoptères - Coccinellidae. Tribu Coccinellini des Régions Paléarctique et Orientale. Société Nouvelle des Éditions Boubée, Paris, $568 \mathrm{pp}$.

JAENIKE J. 1990: Host specialization in phytophagous insects. Annu. Rev. Ecol. Syst. 21: 243-273.

Kesten U. 1969: Zur Morphologie und Biologie von Anatis ocellata (L.) (Coleoptera, Coccinellidae). Z. Angew. Entomol. 63: 412-455.

Klausnitzer B. 1968: Zur Biologie von Myrrha octodecimguttata (L.) (Col., Coccinellidae). Entomol. Nachr. 12: 102-104.

Klausnitzer B. \& Klausnitzer H. 1997: Marienkäfer. Die neue Brehm Bücherei 451, Westarp Wissenschaften, Magdeburg, Germany, 175 pp.

Klingauf F. 1967: Abwehr- und Meidereaktionen von Blattläusen (Aphididae) bei Bedrohung durch Räubern und Parasiten. Z. Angew. Entomol. 60: 269-317.

Liu J., Wu K., Hopper K.R. \& Zhao K. 2004: Population dynamics of Aphis glycines (Homoptera: Aphididae) and its natural enemies in soybean in northern China. Ann. Entomol. Soc. Am. 97: 235-239.

MAJerus M.E.N. 1988: Some notes on the 18-spot ladybird (Myrrha octodecimguttata L.) (Coleoptera: Coccinellidae). Br. J. Entomol. Nat. Hist. 1: 11-13.

Majerus M.E.N. 1994: Ladybirds. New Naturalist Series no. 81. HarperCollins, London, $367 \mathrm{pp}$.

MichaUd J.P. 2005: On the assessment of prey suitability in aphidophagous Coccinellidae. Eur. J. Entomol. 102: 385-390.

Mignault M.-P., Roy M. \& Brodeur J. 2006: Soybean aphid predators in Québec and the suitability of Aphis glycines as prey for three Coccinellidae. BioControl 51: 89-106.

Mills N.J. 1981: Essential and alternative foods for some British Coccinellidae. Entomol. Gaz. 32: 197-202.

OMKaR \& Mishra G. 2005: Preference-performance of a generalist predatory ladybird: a laboratory study. Biol. Control 34: 187-195.

OmKar, Gupta A.K. \& Pervez A. 2006: Attack, escape and predation rates of larvae of two aphidophagous ladybirds during conspecific and heterospecific interactions. Biocontrol Sci. Technol. 16: 295-305.

Rana J.S., Dixon A.F.G. \& Jarošík V. 2002: Costs and benefits of prey specialization in a generalist insect predator. J. Anim. Ecol. 71: 15-22.

Scheurer S. 1971: Der Einfluß der Ameisen und der naturlichen Feinde auf einige an Pinus sylvestris L. lebende Cinarinen in der Dübener-Heide (DDR). Pol. Pis. Entomol. 41: 197-229.

Schmidt-Nielsen K. 1984: Scaling: Why is Animal Size So Important? Cambridge University Press, Cambridge, 256 pp.

Schoonhoven L.M., Jermy T. \& VAN LoOn J.J.A. 1998: InsectPlant Biology. From Physiology to Evolution. Chapman-Hall, London, 409 pp.

Siegel S. \& Castellan N.J., JR. 1988: Nonparametric Statistics for the Behavioral Sciences. 2nd ed. McGraw-Hill, New York, $399 \mathrm{pp}$.

Sloggett J.J. 2008: Habitat and dietary specificity in aphidophagous ladybirds (Coleoptera: Coccinellidae): explaining specialization. Proc. Neth. Entomol. Soc. Meet. 19: 95-113.

Sloggett J.J. \& Lorenz M.W. 2008: Egg composition and reproductive investment in aphidophagous ladybird beetles (Coccinellidae: Coccinellini): egg development and interspecific variation. Physiol. Entomol., in press.

Sloggett J.J. \& Majerus M.E.N. 1994: The Cambridge Ladybird Survey 17: 13-14.

Sloggett J.J. \& Majerus M.E.N. 2000a: Habitat preferences and diet in the predatory Coccinellidae (Coleoptera): an evolutionary perspective. Biol. J. Linn. Soc. 70: 63-88.

Sloggett J.J. \& Majerus M.E.N. 2000b: Aphid-mediated coexistence of ladybirds (Coleoptera: Coccinellidae) and the wood 
ant Formica rufa L.: seasonal effects, interspecific variability and the evolution of a coccinellid myrmecophile. Oikos $\mathbf{8 9}$ $345-359$.

Sloggett J.J., Völkl W., Schulze W., Graf von der SchulenBURG J.H. \& MAJERUS M.E.N 2002: The ant-associations and diet of the ladybird Coccinella magnifica (Coleoptera: Coccinellidae). Eur. J. Entomol. 99: 565-569.

Stewart L.A., Hemptinne J.-L. \& Dixon A.F.G. 1991: Reproductive tactics of ladybird beetles: relationships between egg size, ovariole number and developmental time. Func. Ecol. 5: 380-385.
Tauber M.J., Tauber C.A., Ruberson J.R., Milbrath L.R. \& Alburquerque G.S. 1993: Evolution of prey specificity via 3 steps. Experientia 49: 1113-1117.

Ueno H. 2003: Genetic variation in larval period and pupal mass in an aphidophagous ladybird beetle (Harmonia axyridis) reared in different environments. Entomol. Exp. Appl. 106: 211-218.

WARE R.L. \& MAJERUs M.E.N. 2008: Intraguild predation of immature stages of British and Japanese coccinellids by the invasive ladybird Harmonia axyridis. BioControl 53: 169-188.

Received October 15, 2007; revised and accepted January 28, 2008 